\title{
A brute indicator for a NEET case. \\ Genesis and evolution of a problematic concept and results from an alternative indicator.
}

This is a draft article. Final version published in: Serracant, Pau (2014). A Brute Indicator for a NEET Case: Genesis and Evolution of a Problematic Concept and Results from an Alternative Indicator, in Social Indicators Research, 117:401-419, DOI 10.1007/s11205-0130352-5

\begin{abstract}
This article analyses the NEET (Not in Education, Employment or Training) concept and related indicators and its effects on both youth policies and the perception of young people. It is argued that a "weak version" of social exclusion is often used to explain the phenomenon. This leads both to defective policies (as a "victim blaming" approach tends to be developed instead of structural policies) and to the negative labelling of the NEET young people (as research and policies tend to focus on the individual's deficits and thus associate them with negative values). An alternative indicator is proposed, aimed at reducing the heterogeneity of the situations the concept includes and focus on the core NEET group. This restricted concept centres on those individuals who do not seem to have any objective impediment to study or work. Figures are calculated for the Spanish region of Catalonia and results show a lower proportion of people in a NEET situation; that the NEET rates for young people and adults are similar; that the phenomenon is not new; and confirm that it is related to the risk of social exclusion. These results reinforce the need for an approach which is more sensitive to inequalities to improve our understanding of the NEET population and to avoid the stigmatisation of individuals, generations and countries.
\end{abstract}

\section{Keywords}

Social indicators; vulnerability; NEET; youth transition; welfare regimes; stigmatisation.

\section{Introduction}

The NEET (Not in Education, Employment or Training) concept has become an important tool to analyse school-to-work transitions, as it highlights processes that previously received much less attention and that eventually may lead to social exclusion. However, the consolidation of the NEET international indicator (used by Eurostat and the OECD) and its associated media and political dissemination have generated an unexpected outcome that exemplifies the connections between the moral and scientific understanding of particular situations and groups.

In the Spanish region of Catalonia, and in the whole of Spain, the descriptive acronym NEET has become a negative label that has contributed to stigmatize the whole of the younger generations. The Spanish expression for the NEET concept is "ni-ni", referring to those people who neither study nor work. However, the media and popular understanding of this group consider that is formed by those people who neither want to study nor want to work. Thus, the NEET people are linked to counter-values such as idleness, effort-avoidance and, in the end, to the "values crisis". The fact that Catalonia and Spain have a high NEET rate extends the negative connotations to the whole of the younger generation, which has been labelled as the "Generación ni-ni".

Moreover, the fact that the NEET rate tends to be higher in Southern Europe reinforces those views that link the economic crisis in these countries with the attitudes and values of 
people rather than with the structural constrains and welfare structures. This negative labelling of the people in a NEET situation, however, tends to occur everywhere, regardless of the NEET rate.

This article proposes an indicator that attempts to delimitate the group of people who do reject the functional role of studying and working (those that could be considered to be the core NEET group), in order to see to what extent they form the majority of people in a NEET situation. The results offer an alternative view on the extension of the NEET problem and delimitate a more homogenous group for policy making.

\section{Analysing the NEET concept and indicators}

\subsection{Genesis and evolution of the concept}

In the UK in 1988, most young people aged 16 to 18 years were declared ineligible to receive unemployment benefits and were therefore excluded from the "unemployed" administrative category as all of the members of this age group were supposed to be in employment, in education or training. However, Istance et al. (1994) found that some of the young people were not engaged in any of these activities. They called them "Status0" but, "partly for political reasons and partly to clarify a concept whose meaning was not immediately clear" this expression was finally replaced with the term NEET (Not in Education, Employment or Training) in the academic and political debate (Furlong 2006: 554). In a report by the Social Exclusion Unit (1999) of the British government defined the NEET population as young people aged 16 to 18 years "who neither participate in education or training nor have a job" (Furlong, 2006: 15) and are, therefore, at risk of social exclusion. This report has a key role as it supports the subsequent design and completion of programmes specifically aimed at this group, usually based on motivating the receiver to have a positive attitude towards work and eventually become EET (Yates and Paine 2006). Thus, the emergence of the NEET concept and related policies came about as a result of the exclusion of this group of people from the administrative category of unemployment.

Once consolidated in the UK, the concept was adopted by some international organisations: in 2007 the European Commission offered the first figures on this group in its annual report "Employment in Europe"; and the OECD incorporated the indicator in its "Education at a Glance" report in 2010. Afterwards, in the communication "Youth on the Move", the European Commission set the objective of establishing "a systematic monitoring of the situation of young people not in employment, education or training (NEETs) on the basis of EU-wide comparable data" (European Commission 2010b: 37). In 2011, the Eurostat, the Directorate-General for Employment, Social Affairs and Inclusion and the member states reached an agreement to define the concept: it referred to the unemployed and inactive population who are not in any form of training or education; and is applied to young people aged 15 to 34 years. The objective of the indicator is to identify, within the framework of the European Employment Strategy, the group of non-employed young people who are not developing actions to improve their human capital.

\subsection{Characteristics of the NEET population and outcomes}

The different research studies of the factors linked to (a higher probability of) being in a NEET situation offer similar and complementary results. Qualitative and quantitative studies ${ }^{1}$ carried out in the UK of NEET young people aged 16 to 18 years have identified the following sets of

1 See, for example, Coles et al. (2010), Copps and Keen (2009), Furlong et al. (2012), Pemberton (2008), Robson (2008), Thompson (2011), Eurofund (2011) or the researches of the Department for Education (1999, 2006, 2008 and 2010) and the Social Exclusion Unit (1999) of the British government. 
factors: inequality variables; personal situations; family and environment variables; bad experiences in the educational system; or failures of education system.

Most European studies on the NEET population are based on a broader group (mostly 15 to 34 years) and confirm the influence of many of these factors. As the age range is extended, the relevance of the education level increases and the age of the individual appears as an important variable (Oliver 2011).

All these factors constitute a wide range of situations and attitudes that can be found among the NEET population. Of particular interest to this article is a qualitative research carried out on the Spanish NEET people (Navarrete 2011), which analyses the phenomenon considering both the young people's objective situation and their attitudes towards studying or working. Results show a clear gradation: on one extreme, there are those inactive non-studying young people who are somehow looking for a job or considering returning to studying; on the opposite extreme, there are those young people who specifically reject what the author calls the "functional role" of working or studying.

The negative outcomes of being in a NEET situation have also been extensively analysed $^{2}$ and three main types have been identified: economic and professional; social and cultural; and health related outcomes. Both the characteristics of the population who are in NEET situations and their outcomes have proved that the phenomenon is linked to the structure of social inequalities and constitutes a risk of social exclusion.

\subsection{Criticisms of the concept and related indicators}

Research on the NEET population has increased our understanding of the phenomenon and helped the design of public policies. However, the expansion and consolidation of the NEET concept has occurred despite some problems dating from its beginnings that have not been solved yet:

(1) Heterogeneity. The main criticism of the NEET concept refers to the major diversity of situations that it includes (Furlong 2006). This particularly (but not solely) occurs in the European operationalization of the concept: the size of the age group to which the indicator refers enlarges the potential number of individuals and situations and weakens its link to social exclusion. The indicator includes situations such as having family commitments, being in a gap year, being disabled or ill, volunteering, actively looking for a job, etc. A significant number of the situations potentially included in the operationalization of the indicator contradict its purpose of detecting situations that may lead to social exclusion. Furthermore, the addition of diverse situations that may be effectively related to social exclusion (but due to different reasons) does not facilitate our understanding of reality or policy making.

(2) Individualization. The concept is more commonly used to refer to people than situations, which leads research and intervention on the phenomenon to tend to focus on individuals and their shortcomings (a "weak" understanding of social exclusion) more than on social inequalities and failures of social policies (a "strong" version of social exclusion) (Thompson 2011; Robson 2008). However,

"the experiences of NEET young people cannot be accounted for purely in terms of the dispositions of the individuals and the choices they make. Subjective factors are important, but they are embedded in and arise from objective conditions, including local structures of opportunity and more general interactions between labour markets and the social distribution of educational achievement" (Thompson 2011: 798)

2 See the aforementioned studies by Coles et al. (2010), Barham et al. (2009), Copps and Keen (2009), Eurofund (2011) and the Social Exclusion Unit (1999); see also Quintini and Martin (2006) and Bynner and Parsons (2002). 
(3) Completion of defective policies. This individualizing approach to the concept has led, according to some authors, to the completion of defective policies. Programmes are sometimes mostly orientated at achieving a change in status (from NEET to EET), which may lead to a focus on the less vulnerable individuals and a lack of attention to the "workrelated security" (Standing 2008). According to Thompson (2011), class-based inequalities within education and employment must be addressed. Related to this, some authors consider that in many cases being in a NEET situation is merely a symptom of another problem, which is what really has to be solved (Yates and Payne 2006).

(4) Oblivion of other groups. The increase in studies and interventions targeting the NEET group might have diminished the attention and resources necessary for other risk groups. Robson (2008) explains that in the UK the debate on the NEET group has replaced the focus on youth unemployment, even though the situation of the long-term unemployed is especially vulnerable. Furlong (2006) considers the NEET concept to be based on the employed/unemployed dichotomy, which is not the most appropriate for analysing the trajectories of young people, which are marked by precariousness and occupational discontinuity.

(5) Youngness of the phenomenon. Finally, being unemployed or inactive and not studying is a situation that occurs in all age groups; however, the different NEET indicators only refer to young people. Two articles mention this: in their analysis for the OECD, Quintini and Martin (2006) explain how there are twice as many young than adult NEETs, which leads them to focus their analysis on the former. Barman et al. argue that "the interest is particularly on young people due to the possible implications that being NEET may have on future labour market experiences" (Barham et al. 2009: 25). Certainly, what occurs during the youth phase may have long-term consequences and situations of vulnerability may tend to increase over time (Halleröd and Bask 2008); but, on the other hand, events that happen during the youth transition are reversible; and the immediate consequences of being in a NEET situation may be equally or more negative at other stages of life, especially considering that many young people live in their parental home: the new "precariat" (Standing 2011) does not only consists of young people; instead, the secondary market of poor work is accessed by both young people and their parents (Shildrick and MacDonald 2007). It is also true that youth is the life-phase in which individuals receive their basic training; but it must also be considered that younger generations tend to surpass the education level of older generations: so, the decision not to study if one is unemployed or inactive, if it has to be understood in negative terms (something debatable), should not solely refer to younger generations. In our opinion, further research is needed to analyse the main age-related differences of being in a NEET situation and to justify the decision of excluding adult people from this category, especially with regard to the international standard indicator.

\subsection{Negative labelling of young people}

The apparently descriptive acronym NEET was created to replace the expression "Status 0", partly to avoid its negative connotations; however, the NEET label also may increase the marginalisation and stigmatisation of this group (Thompson 2011). The individualizing approach to the NEET concept is directly linked to its negative connotations (MacDonald 2011): the NEET case exemplifies what might be characterized as "victim-blaming', or more neutrally, individualizing employment policies" (Cole 2008: 28). This approach has linked young people that are in this situation both to marginalisation and negative values such as idleness, conformism and, eventually, the "values crisis" as the underneath (popular, media and often academic) assumption on the NEET people is that they do not want to study or work (Robson, 2011). This process reminds us of the moral panics described by Cohen (1973). 
This negative perception of young people in a NEET situation may occur in the UK (Colley and Hodkinson 2001; MacDonald 2011; Thompson 2011) but also in other countries where the concept has had media coverage. Inui (2005) explains that in Japan the media are especially critical of this group. In Spain, the concept (not the expression) started to be systematically used following a Catalan trade union annual report (UGT, 2005). It was journalist J.L. Barbería, in an article published in El País in June 2009, who popularized the label "Generación ni-ni". The label refers to the young population in general, which are supposed to neither study nor work. In 2010, a television reality show called "Generación ni-ni" was released. This generational labelling is linked to the fact that Catalonia and Spain have the second and fifth highest NEET rate in Europe (Fig. 1).

\section{FIG. 1 HERE}

This process implies, in our opinion, the attribution of a "generational personality" (Nico, 2012) that reminds us of Bourdieu's (1997) "biographical illusion". Thus, the different types of transitions of the old and new generations would be explained by a generational flaw linked to the defective values and attitudes of the young people. Additionally, the different NEET rates could be explained by each country's values system and not by their structural and institutional characteristics (a "cultural illusion" as described by Nico, 2012). Thus, the negative values associated to the NEET concept can reach individuals, generations and countries.

\section{A proposed indicator}

\subsection{Objectives and restrictions}

The NEET concept has encouraged research that has highlighted different situations close to the risk of social exclusion that previously received less attention. However, the objections explained in the previous section question the capacity of the concept to define a relatively homogeneous group that could become a specific target for effective policy making. This occurs especially in the Eurostat and OECD's definition and operationalization of the concept, which increased the deficits of the indicator: the broadening of the age-range and situations included enhanced its heterogeneity and therefore reinforced its related problems. Moreover, the enlarged results may increase a negative perception of young people. Being its main objective to study "labour market vulnerability among young people" (Furlong 2006: 554), there are other concepts and indicators that define more homogeneous groups and situations. Furlong argues that "to represent vulnerable youth effectively we must either use a set of definitions that are narrower than that represented by NEET, or adopt a much broader definition that provides a basis for more far-reaching interventions" (2006: 553).

This study develops the first option and proposes a new indicator for the NEET population ("NEET-restricted" indicator) that is both a complement and an alternative to the OECD/Eurostat standard NEET indicator. This effort aims to reduce the heterogeneity of the situations that can be included in the NEET indicator and thus get closer to what could be considered the central NEET group. This more precise definition of the NEET population, which would be closer to the risk of social exclusion, should facilitate its posterior analysis and policy making.

Our approach to the central NEET situation is based on the aforementioned research by Navarrete (2011), which considers the circumstance of not wanting to adopt the "functional role" of working or studying as the defining characteristic of the core group members. This characteristic makes it possible to distinguish them from other groups of people (such as the unemployed or the sick) that do not adopt any of these roles since they have an objective impediment. Thus, the NEET-restricted indicator will refer to the population who do not work or study and do not wish to do so. 
The NEET-restricted indicator is based on the OECD/Eurostat NEET indicator and therefore uses the Labour Force Survey ${ }^{3}$. The indicator is achieved by means of eliminating, from the OECD/Eurostat indicator, those circumstances that a) can be considered to be situations of working or studying; and/or b) can be considered to be situations that suppose an objective impediment to working or studying. Concretely, the NEET-restricted indicator focuses on the people who accomplish each of next conditions:

(1) Are not studying. This condition, which is common to the previous NEET indicators, has excluded a particular group from the new indicator- some "hidden" students: a detailed revision of the questionnaire and dataset of the Catalan LFS has revealed a small portion of people that the author has considered to be students. It is the case of those people who, according to the LFS dataset, are non-students but who declared that they could not start working because they are waiting for their studies to start.

(2) Are not working. This condition is also supposed to be common to the previous NEET indicators. However, it has introduced two new constraints in the NEET-restricted indicator. The first restriction affects reproductive work: unpaid reproductive work is a type of work and therefore does not fit with the idea of passive inactivity that lies behind the proposed NEET-restricted concept: if we attempt to exclude from the indicator those people that want or do work or study, it is clear that unpaid reproductive work is a type of work and therefore these people should be excluded. Including them only reinforces, with the NEET label, the negatives connotations that reproductive unpaid work still carries. On the other hand, among these people there may be some groups that do not wish to enter the labour market and have a paid job. This is especially worrying with regard to teenage mothers, and no doubt they require (specifically designed) intervention programmes. Finally, the extension of the age-range of the international indicator provokes that most of the people included in this category are 25 to 34 years old mothers who have temporary stopped their careers in order to take care of their recently born children and many of them can by no means be considered an at risk group. To sum up, we consider that, despite of the fact that some of the inactive non-studying young women may be in a vulnerable position and require specific intervention programmes, it cannot be said that the majority of those that form this group reject the role of working or studying and are in risk of social exclusion. People who do reproductive work as their main activity have therefore been excluded from the indicator.

The second restriction is more limited and affects those people that are in a labour force adjustment plan. The explicit relation to work of this procedure is the reason why people who are in this situation have also been excluded from the indicator.

(3) Are not looking for a job. Eurostat considers unemployed people to be those who do not work but are actively looking for a job. Unemployment refers to a situation in which the individual wants to work but cannot. This is mostly due to structural reasons and the economic cycle and often has little relation with the individual's decisions and attitudes. Moreover, the unemployment and long-term unemployment indicators are internationally standardised and provide precise information that plays a key role in policy making. Its inclusion in Eurostat and OECD NEET indicator increases its figures dramatically, makes its analysis more difficult and does not help in the design of new interventions. Therefore, unemployed people have been excluded from the indicator.

This decision does not mean to suggest that unemployed non-studying people are in no need of programmes and policies aimed at their problematic, especially considering that most of the unemployed have low qualifications. However, these programmes are long well

3 This decision enables the results of both indicators to be directly compared and provides an alternative view on the issue. In addition, the LFS is an internationally standardised regular survey with a reliable sample that will facilitate monitoring of the evolution of the indicator. 
established and face a problematic of a different nature than that of the NEET-restricted people.

(4) Are not ill or disabled. Disabled or ill people are inactive populations due to reasons alien to their will. Disabled or ill people are inactive populations due to reasons alien to their will. Again, excluding them from the indicator does not pretend to suggest that many of them are not in a difficult situation and do not need specific programmes. In fact, many of them are victims of discrimination and lack support... to study or work. By excluding them from the NEET-restricted indicator we stress that the fact that if they are not working or studying is not due to their will, but to their illness, disability or to the discriminations these may carry with. Therefore, disabled or ill people have been excluded from the indicator.

Finally, it was decided to define and calculate the NEET-restricted indicator for the whole working-age population (from 16 to 64 years). Certainly, the original UK indicator focused on school-to-work transitions, mostly among the (very) young people who abandoned their studies. However, during an economic crisis most of the young people considered to be in a NEET situation are not experiencing the difficulties of early labour market trajectories but are workers that have lost their jobs (dismissal or end of a fixed-term contract). This predominance of "standard" labour market difficulties (as opposed to school-to-work ones) among those in a NEET situation is strongly reinforced by the expansion, in the international indicator, of the age-group up to 29 or 34 years old (most of whom have relatively long working trajectories). Therefore, if the indicator does not focus specifically on school-to-work transitions among the youngest groups but it focuses on "the group of non-employed (young) people who are not developing actions to improve their human capital", then there are no impediments to extend it to the whole of the population.

Surely, as it has been said previously, the long-term effects of being in a NEET situation may be stronger for those young people that cannot overcome this situation; but if the focus is put on social exclusion risks and not only in school-to-work risks, many adult people (and those who depend on them) can be extremely vulnerable in a NEET situation, especially considering their lower educational level (with regard to the younger generations) and the difficulties to find a job at a certain age.

On the other hand, by extending the indicator to the whole of the working-age population, the negative connotations of the NEET labelling become obvious and the generational stigmatisation weakens. Showing the way research and social indicators can help to construct and stigmatised view of particular groups may be considered to be an interesting outcome of this proposal. Thus, the whole of the working-age population has been included in the indicator in order to analyse the results and establish grounds on which the validity of this decision can be assessed.

\subsection{Operationalization and definition of indicator}

Table 1 shows the different situations in which an individual can be and their inclusion or exclusion in the new indicator:

\section{TABLE 1 HERE}

In brief, the "NEET-restricted" indicator refers to the inactive non-studying people aged from 16 to 64 years old who are not ill or disabled and who do not have family commitments as their main activity.

The remaining group is far from being a homogeneous one, as several situations are potentially included (such as people who lack basic skills, who have addiction problems or who show no 
interest in studying or working), each of which will require its own type of intervention ${ }^{4}$. However, the new indicator delimitates more precisely a situation close to the risk of social exclusion and allows its monitoring and the development of more focused policies.

\subsection{The Catalan case}

Results have been calculated for the Spanish region of Catalonia, which has the $3^{\text {rd }}$ highest NEET rate in Europe. It has a population of 7,565,603 people, 1,219,368 of which (16.1\%) are aged 15-29 (Idescat, 2012). Catalonia is an example of the familistic welfare regime characteristic of Southern Europe (Ferrera 1996), which shares some of the outcomes of the conservative model (a medium level of decommodification and a high degree of social stratification) but where the family has a stronger role in providing the individuals with resources. Particularly, Catalonia has a weak welfare state and a labour market characterised by a persistently high unemployment, structural precariousness and an extended black economy in a segmented labour market, in which young people then to be in a vulnerable position. The weakness of both social policies and the labour market tend to emphasize the role of families in the individuals' well-being, especially in the case of young people (Alegre 2011).

\subsection{Impact of the decisions on the results}

The decisions that have been taken have a strong impact on the quantification of the people in NEET situations. Table 2 shows the reduction in the NEET population in Catalonia due to the applied restrictions.

\section{TABLE 2 HERE}

The operationalization of the NEET-restricted indicator lowers the population in a NEET situation by $1,184,700$ people $(-90.3 \%)$ and 231,300 young people $(-88.9 \%)$. Of the total working-age population, $52.3 \%$ of the excluded cases are inactive people who are not studying: these are mostly people that are doing unpaid reproductive work as their main activity. Among young people, such activity is less common and $75.2 \%$ of the excluded cases are unemployed people who are not studying.

\section{Results: people in a NEET-restricted situation in Catalonia}

\subsection{Activity status of the population}

A NEET situation is one of the diverse statuses in which an individual can be with regard to work and studies. We have defined five activity statuses:

$4 \quad$ Nevertheless, the types of situation effectively grasped through the NEETrestricted indicator are probably more delimited than those potentially included. Broadly speaking, it can be argued that within this restricted NEET group there are two opposing types of situations: on the one hand, extreme situations such as having addictions, criminal records, etc.; on the other hand, (former) long-term unemployed people who have lost interest in studying or trying to work but who do not necessarily experience distress or poverty in their situation. However, the situation of the first group of people makes them unlikely to be part of a survey sample (Romaní 2011): qualitative research is needed to identify them and understand their circumstances and needs. Precisely, qualitative research carried out in Spain on the NEET population (Navarrete 2011) found that most of them were in the second type of situation. Nevertheless, it would not be accurate to split the NEET-restricted people into these two separate groups, as there are many in-between situations that form a continuum. 
A) Employment. Employed active population (studying or not).

B) Unemployment. Unemployed active population (studying or not).

C) Inactivity: study. Inactive studying population.

D) Inactivity: NEET-restricted. Inactive non-studying people that are not ill or disabled and that do not have family commitments as their main activity

E) Inactivity: others. Inactive non-studying population with family commitments, ill, disabled or in a labour force adjustment plan.

Table 3 shows the absolute and relative numbers for the distribution of the working age population in Catalonia according to their activity status.

\section{TABLE 3 HERE}

In any age group, the most common status is "employed". Among young people, the second most common status is "inactive: studying", which is the least common status among the older group. In contrast, the second status in this older group is "inactive: others". This is not only due to an age effect (people older than 29 years have overcome their main educational stage) but also to a generational effect (the historical diminishing of unpaid reproductive work as an individual's main activity).

Finally, the least common status among the whole population and among young people is "NEET-restricted": 127,500 people (2.6\% of the working-age population) are in this situation. Adults make up $77.3 \%$ of the NEET population. This distribution reflects the fact that there are more adults than young people, but the former are only $76.1 \%$ of the total. In fact, the NEET rate is higher among the 30-64 age group (2.7\%) than among the 16-29 group (2.5\%). Additionally, it must be considered that absolute numbers are relevant when developing public policies.

These figures lead to two important conclusions. First, being in a NEET situation is a circumstance that occurs in all age groups. For the Catalan case, both absolute and relative figures show that being in a NEET situation is a phenomenon that does not only affect young people; and there is no evidence that confirms the notion that being in this situation is a bigger problem for young people than for adults (especially with regard to the immediate or short term consequences). We therefore believe that there is no current justification for limiting the NEET indicators and study to young people.

Second, the figures show a lower number of people in a NEET situation. The results given by the new indicator re-contextualize the scope of the phenomenon: it is not a generational issue but a marginal, although important, trend. We believe that the reconceptualization of what being in NEET situation means offered by the NEET-restricted indicator makes it possible to delineate more precisely a group that may be a target for specific programs linked, as it will be seen, to the risk of social exclusion.

\subsection{Recent evolution of the activity status}

Table 4 shows the evolution of the activity status of the population between 2005 and 2010, mostly affected by the changes in the "employed" status. From 2007 (last year of employment creation) to 2010, the figures for employed people decreased by $11.0 \%$ and for the unemployed increased by $175.3 \%$; the "inactive: studying" status increased by $8.1 \%$. Finally, the "NEETrestricted" status increased by $27.4 \%$ over this period; however, as the NEET figures are so low, changes in the proportion of NEET people in the whole population situation are also low (from a minimum of $1.9 \%$ to a maximum of $3.3 \%$ ). 


\section{TABLE 4 HERE}

With regard to the differences between young and adult people, the fact that the economic crisis was mostly absorbed in Catalonia by young people meant that the diminishing of the "employed" was much bigger among this group (-31.4\%) than among the older one $(-4.7 \%)$. Another important difference occurs in the "inactivity: others" status: from 2007 to 2010 the proportion of young people in this situation diminished by $46.3 \%$ (10.7\% among the adult population). It might be that the crisis has pushed a significant part of the young people with family commitments to change their activity status.

Broadly speaking, a parallel evolution of the people of "unemployed" and "NEETrestricted" status can be observed. However, higher unemployment could be expected to diminish the NEET figures (as people in this situation would start working or looking for a job to compensate for the reduced family income). This is what happens to people of "inactivity: others" status. However, among the NEET population it happens the contrary: during the 20052010 period, for each of the three age groups, almost in all the inter-annual intervals the indicators evolve in the same direction. Thus, the growth of unemployment seems to be linked to the growth of people in a NEET situation. This suggests that a significant segment of those in a NEET situation are "discouraged unemployed people": probably long-term unemployed people who have diminished or abandoned their attempts to find a job. This shows that being in a NEET situation is directly linked to structural factors, which relativizes the role of the individual's attitudes as the key issue to explain the phenomenon.

\subsection{Young people in a NEET situation in the past}

Another facet to observe is to what extent being in a NEET situation is a new phenomenon linked to the new generations and/or the new economic context. To examine this issue data on the young people that were in a NEET situation during the 90s is presented. Changes in the LFS do not permit direct comparison of these data with the later data.

In 1994, the NEET-restricted rate among people aged 16 to 29 years old was $6.5 \%$; in 1998 the rate was $5.7 \%$. These figures suggest that being in a NEET situation was also (marginally) common in the past. If the phenomenon was not studied, this was simply due to the fact that the concept had not yet been completely constructed. Its formal invention in the UK in 1999 has made it possible to observe a reality that was previously ignored.

We have provided data from two different years to continue observing the relation between NEET status and unemployment: in 1994 in Catalonia there was a major economic crisis that by 1998 had started to diminish. As in the 2000s data, the reduction in the unemployment rate also led to a reduction in the NEET rate. So, in both decades the figures for the NEET population rose during the crisis periods and diminished during the growth periods. This link between the economic crisis and the amount of people in a NEET situation reinforces the author's suggestion that being in a NEET situation is an event related to long-term unemployment, which it has been proved to be a path that frequently leads to social exclusion (Furlong et al. 2003, Furlong 2006 and Kieselbach 2003).

\subsection{Features of the people in a NEET situation}

Since only a small part of the population is in a NEET situation there were too few cases in the Catalan LFS sample to analyse their features. Therefore, in order to have enough cases it was decided to add the samples from the 2005-2010 period. Next it is presented the resulting data from the four variables that were selected to study the NEET group: sex, education level, nationality and (among young people) housing status.

\section{TABLE 5 HERE}

Three quarters of the total working-age population in a NEET situation are women. However, this distribution is not the same among the different age groups, as among young people the 
proportion of girls is fairly similar to that for boys. A generational change probably lies behind this difference, as in Catalonia and Spain girls have a much higher education level and activity status than older women. In fact, the table also shows that the education level is linked, in all age groups, to the probability of being in a NEET situation. However, the fact that more than a third of the young people in a NEET situation have an ISCED 3-6 degree shows the complexity of the phenomenon and the mechanisms through which individuals reach this status.

The individual's nationality also affects the probability of being in a NEET situation depending on the age group. In both cases, non-nationals are overrepresented among NEETs, but among young people this trend is much stronger. Finally, young people who have already left the parental home are overrepresented among the people in a NEET situation, which contradicts assumptions regarding this group.

Broadly speaking, of the people aged over 29 years old, those who are in NEET situations share many of the features of the "inactive: others" group. This suggests that, in the adult group, being in a NEET situation is somehow associated to having family commitments, which are usually undertaken (as a main activity) by women. Women are, precisely, the majority of the NEET people in this age group. However, this resemblance weakens in the younger group, as the proportion of women falls and the proportion of non-nationals rises; in contrast, the group's features are close to those of unemployed young people. Therefore, among the young people, the NEET group has its own profile, which is distinctive from the other activity statuses but close to the profiles in which social exclusion is more likely to occur. These results correspond with the British studies of 16 to 18 year olds in a NEET situation and with those carried out on a European level using the standard NEET indicator, which highlight the importance of the inequality variables.

\subsection{NEET-restricted vs NEET-standard features}

Table 5 also compares the profiles of both the people in a NEET-restricted situation (as defined in this paper) and in a NEET-standard situation (as defined by the OECD-Eurostat indicator). Two of the three variables (sex and educational level) show very similar results in both indicators: those less educated are much more likely to be in a NEET-restricted and NEETstandard situation; and women are more likely to be in both these situations, especially those aged over 30. However, the results change when considering the nationality of those in a NEETrestricted and NEET-standard situation: non-national people are $17.4 \%$ of the total population; $21.3 \%$ of the NEET-standard group; and $28.3 \%$ of the NEET-restricted group. If we focus on the young people, the non-national people are much more over-represented: $24.2 \%, 40.7 \%$ and $51.5 \%$. Being the nationality a risk factor, especially among the Catalan young people (Alarcón and Alcalde, 2010), this result suggests that those that are in a NEET-restricted situation are closer to the risk of social exclusion that those in a NEET-standard situation. This is consistent with the main criticism of the standard indicator previously mentioned, i.e. its heterogeneity, which includes a variety of situations ranging from social exclusion to (in some extreme cases) privilege, including many situations that should not be considered to constitute a risk.

\section{Discussion}

\subsection{Youth research, policy making and the media}

The results of the NEET-restricted indicator provide evidence that being in a NEET situation is not a) a majority phenomenon; b) solely a young people's issue; and c) a completely new phenomenon linked to the current young generations. Most of the people that the international indicator considers to be in a NEET situation do have a positive attitude with regard to working and studying. Therefore, the link between being in a NEET situation and a passive attitude to labour only could be applied to a small part of the population (both young and adult people) and is by no means related to all of the young people that the international indicator considers to be 
in a NEET situation. In the Catalan case, the high NEET rate has contributed to the negative labelling of a complete generation and its association with the debate on the "values crisis".

The NEET case exemplifies the processes of labelling of young people to which youth research sometimes contributes (París et al. 2006): a distorted perception of young people (often associated to moral panics) creates social demands for public policies to amend them; policies often based on research (or indicators) that is solely addressed at young people and that, when disseminated, provides the media with arguments to reinforce the negative values associated with the young person, the young generations and the countries where the phenomenon is more common. Thus, our analysis is a case study of the effects social indicators may have on the negative labelling of particular social group and it shows, as Møller et al. (2010) did for the case of tuberculosis, the connections between the moral and scientific understanding of the NEET situation.

\subsection{NEET-restricted situation and the risk of social exclusion}

To what extent is it possible to argue that being in a NEET-restricted situation constitutes a risk of social exclusion? The statistical source used to build up the indicator does not allow the author to fully explore this issue. However, the data that has been shown clearly suggests this link and stimulates further research to understand these processes entirely. Thus, the link between economic crisis, unemployment and NEET-restricted situation, on the one hand; and the features of vulnerability of those segments of population that are in this situation, on the other hand, are strong cases to defend the link between the NEET-restricted situation and the risk of social exclusion. However, the main argument to be considered is that the NEETrestricted situation focuses on the core segment of the NEET-standard indicator, and there is a strong consensus about the fact that this particular group is a specifically vulnerable one. Actually, as it has been explained, the NEET-restricted concept is similar to the one used by Navarrete (2011) in his qualitative research, in which he finds most of the members of this group to be in a marginal situation and without a hope of improvement.

Thus, the programs that have proved to be the most adequate for the NEET-core group (those that focus on soft more than on hard skills) would be appropriate to address the people in a NEET-restricted situation. It could be therefore argued that the programmes devoted to the NEET phenomenon should focus on this core group and use this comprehensive approach; on the other hand, many of the people that have been included in a NEET programme could be considered to enter a standard employment programme.

\subsection{Youth trajectories, individual choice and welfare regime}

The negative connotations of the "NEET label" are linked to the individualising ("weak" or "victim-blaming") approach to the concept. This research reinforces the criticisms to this approach: firstly, it has shown that the vast majority of the situations included in the international indicator constitute an objective constraint to educational or labour participation. Certainly, some of these constraints may be related to the individuals' skills or characteristics; however, the lack of interest to study or work is not one of their features. Secondly, among those people included in the NEET-restricted indicator, the close connection between the NEET-restricted rate and the economic cycle shows the influence of the structural factors on their situation, decisions and attitudes. This exemplifies the fact that the individual's decisions do not depend solely on their attitudes and cultural background but "it must be acknowledged that the new economy is failing to create long-term employment stability for a significant number of young people" (Furlong 2006: 567). Discontinuous trajectories can be the outcome of structural constraints among the less favoured and not only the expression of choice (McDonald et al. 2011). Therefore, an approach which is more sensitive to societal transformations and social inequalities is needed to study the NEET phenomenon.

In the case of Catalan young people, the NEET pathways should be analysed as a part of the young people's vulnerable transitions to work in the context of the Mediterranean 
employment model (Alegre 2010) and the familistic welfare regime (Van de Velde 2008): unemployment, fixed-term contracts and continuous entrance and exit of employment are structural features for young people that are derived from a strong age-based labour market segmentation (O'Reilly et al. 2011). An important part of the young people who are unemployed, in a NEET situation or in precarious jobs endure these circumstances under the family umbrella. This familistic regime reinforces intergenerational and intragenerational inequalities: on the one hand, it benefits the older generations, as the Catalan and Spanish weak social policies could not guarantee the current living conditions of most households if vulnerability in the labour market was, in age-terms, more evenly distributed (CES 2006). Busetta and Milito (2010) also consider this situation to be characteristic of Italy, another representative of a familistic welfare regime. On the other hand, the important polarization of educational attainment among young people linked to a strong labour market segmentation favours intragenerational inequalities (Alegre 2010). Thus, both the high NEET-standard rate and the low NEET-restricted rate should be mostly explained by the impact the familistic welfare regime has on youth transitions in Catalonia.

\subsection{Coda}

This study redefines the NEET concept and proposes an alternative operationalization of the indicator that reduces significantly the heterogeneity and figures of the international standard indicator. This deconstruction of the standard indicator was the main objective of the paper and it has shown revealing results The analysis of the NEET international indicator and the process of construction of the NEET-restricted indicator have shown that most of the people that the first considers to be in a NEET situation do have a positive attitude with regard to working or studying. Moreover, results from the NEET-restricted indicator suggest a connection between the NEET rate and the economic cycle, which exemplifies the influence of the structural factors on the individual's situation, decisions and attitudes. These conclusions reinforce the criticisms to those policies with a "victim blaming" or individualizing perspective on the NEET case. It has also reinforced the link between being in a NEET situation and the risk of social exclusion; however, the length of this paper and the statistical source that has been used do not allow an in depth study of this issue. Additional research is required to identify the different needs of the NEET group, according to their situation and age, and of the processes that lead an individual to be in and to escape from this situation. 


\section{References}

Alarcón, A. and Alcalde, R. (2010). Joves d'origen immigrant a Catalunya. Necessitats $i$ demandes. Una aproximació sociológica. Barcelona: Secretaria de Joventut.

Alegre, M.A. (Dir.) (2010). El règim de benestar juvenil a Catalunya. Fonts de benestar i oportunitats transicionals dels joves catalans [The welfare youth regime in Catalonia]. In: Secretaria de Joventut Pla Nacional de Joventut 2010-2020. Síntesi dels estudis d'avaluació realitzats per la Secretaria de Joventut (pp. 20-37). Barcelona: Secretaria de Joventut.

Barham C., Walling, A., Clancy, G., Hicks, S. and Barham, S. (2009). Young people and the labour market. Economic and Labour Market Review, 3(4), 17-29.

Bourdieu, P. (1997). Razones prácticas. Sobre la teoría de la acción [Practical reason. On the theory of action]. Barcelona: Anagrama.

Busetta, A. and Milito, M. (2010). Socio-Demographic Vulnerability: The Condition of Italian Young People. Social Indicators Research, doi: 10.1007/s11205-009-9507-9

Bynner, J., Parsons, S. (2002). Social Exclusion and the Transition from School to Work: The Case of Young People Not in Education, Employment, or Training (NEET). Journal of Vocational Behaviour, 60(2), 289-309.

CES (2006). El papel de la juventud en el sistema productivo español [The role of youth in the Spanish productive system]. Madrid: CES.

Cohen, S. (1973). Folk Devils and Moral Panics. St Albans: Paladin.

Cole, M. (2008). Sociology contra government? The contest for the meaning of unemployment in UK policy debates. Work, Employment and Society, 22(1), 27-43

Coles, B., Godfrey, C., Keung, A., Parrot, S. and Bradshaw, J. (2010). Estimating the life-time cost of NEET: 16-18 year olds not in Education, Employment or Training. York: The University of York.

Colley, H. and Hodkinson, P. (2001). Problems with Bridging the Gap: the reversal of structure and agency in addressing social exclusion. Critical Social Policy, 21(3), 335-359.

Copps, J. and Keen, S. (2009). Getting back on track. Helping young people not in education, employment or training in England. London: New Philanthropy Capital.

Department for Children, Schools and Families (2010). Participation in education, training and employment by 16-18 year olds in England. www.education.gov.uk Accessed 12 May 2011.

Department for Education (2010). NEET Statistics- Quarterly Brief. www.education.gov.uk Accessed 12 May 2011.

Department for Education and Employment (2006). Participation in education, training and employment by 16-18 year olds in England: (2004) and (2005). www.education.gov.uk Accessed 12 May 2011.

Department for Education and Skills (1999). Statistical Bulletin 11/(1999). www.education.gov.uk Accessed 12 May 2011. 
Eurofund (2011). Young people and NEETs in Europe: First findings www.eurofound.europa.eu (accessed 6 August 2012).

European Commission (2007 and 2010a). Employment in Europe. Directorate-General for Employment, Social Affairs and Equal Opportunities.

European Commission (2010b). Youth on the Move. An initiative to unleash the potential of young people to achieve smart, sustainable and inclusive growth in the European Union. Luxembourg: Publications Office of the European Union.

Ferrera, M. (1996). The "Southern Model" of Welfare in Social Europe. Journal of European Social Policy, 6(1), 17-37.

Furlong, A. (2006). Not a very NEET solution: representing problematic labour market transitions among early school leavers. Work, Employment and Society, 20(3), 553-569.

Furlong, A., Cartmel, F., Biggart, A., Sweeting, H. and West, P. (2003). Youth Transitions: Patterns of Vulnerability and Processes of Social Inclusion. Edinburgh: Scottish Executive Social Research.

Furlong, A. and Cartmel, F. (1997). Young People and Social Change: Individualisation and Risk in the Age of High Modernity. Buckingham: Open University Press.

Furlong, A., Inui, A., Nishimura, T. and Kojima, Y. (2012). Accounting for the early labour market destinations of 19/20-year-olds in England and Wales and Japan. Journal of Youth Studies, 15(1), 1-15.

Halleröd, B. and Bask, M, (2008). Accumulation of Welfare Problems in a Longitudinal Perspective. Social Indicators Research, doi: 10.1007/s11205-007-9192-5

Idescat (2012). Continuous population census. Barcelona: Idescat.

Inui, A. (2005). Why Freeter and NEET are Misunderstood: Recognizing the New Precarious Conditions of Japanese Youth. Social Work \& Society, 3(2), 244-251.

Istance, D., Rees, G. and Williamson, H. (1994). Young People Not in Education, Training or Employment in South Glamorgan. Cardiff: South Glamorgan Training and Enterprise Council.

Kieselbach, T. (2003) Long-Term Unemployment Among Young People: The Risk of Social Exclusion. American Journal of Community Psychology, 32(1-2), 69-76.

OECD (2010). Education at a Glance 2010. OECD Indicators. OCDE.

O'Reilly, J., Lain, D., Sheehan, M., Smale, B. and Stuart, M. (2011). Managing uncertainty: the crisis, its consequences and the global workforce. Work, Employment and Society, 25(4), 581595.

MacDonald, R. (2011). Youth transitions, unemployment and underemployment. Journal of Sociologya, 47(4), 427-444.

McDonald, P., Pini, B., Bailey, J. and Price, R. (2011). Young people's aspirations for education, work, family and leisure. Work, Employment and Society, 25(1), 68-84 
Navarrete, L. (Dir.) (2011). Desmontando a ni-ni. Un estereotipo juvenil en tiempos de crisis [Deconstructing ni-ni. A youth stereotype in times of crisis]. Madrid: Instituto de la Juventud.

Møller, V., Erstad, I. and Zani, D. (2010). Drinking, Smoking, and Morality: Do 'Drinkers and Smokers' Constitute a Stigmatised Stereotype or a Real TB Risk Factor in the Time of HIV/AIDS? Social Indicators Research, doi: 10.1007/s11205-009-9546-2

Nico, M. (2012). Transições para a vida adulta em Portugal: para lá da ilusão cultural [Transitions to adulthood in Portugal: beyond the cultural illusion]. Le Monde Dilpmatique, Ediçaõ Portuguesa. April.

Oliver, J. (Dir.) (2011). Índice laboral. Junio, 2011. www.manpower.es Accessed 10 June 2011.

París, P., Serracant, P. and Tintoré, M. (2006). La recerca sobre joventut a Catalunya [Youth research in Catalonia]. Papers, 79, 285-317.

Pemberton, S. (2008). Tackling the NEET generation and the ability of policy to generate a "NEET" solution - evidence from the UK. Environment and Planning C: Government and policy, 26, 243-259.

Quintini, G. and Martin, S. (2006). Starting well or losing their way? The position of youth in the labour market of the OECD countries. OECD Social, Employment and Migration Working Papers, 39. www.oecd.org Accessed 13 May 2011.

Robson, K. (2008). Becoming NEET in Europe: A Comparison of Predictors and Later-Life Outcomes. Paper presented at the Global Network on Inequality Mini-Conference, New York, February.

Romaní, O. (2011). La epidemiología sociocultural en el campo de las drogas: contextos, sujetos y sustancias [Sociocultural epidemiology in the field of drugs: contexts, subjects and substancies]. In: J.A. Haro (Dir.) Epidemiología sociocultural. Un diálogo en torno a su sentido, métodos y alcances (pp. 89-113). Buenos Aires: Lugar Editorial.

Shildrick, T. and MacDonald, R. (2007). Biographies of exclusion: poor work and poor transitions. International Journal of Lifelong Education, 26(5), 589-604.

Social Exlcusion Unit (1999). Bridging the Gap: New Opportunities for 16-18 Year Olds not In Education, Employment Or Traning. London: Social Exclusion Unit.

Standing, G. (2008). Economic insecurity and global casualisation - threat or promise? Social Indicators Research, doi: 10.1007/s11205-007-9202-7

Standing, G. (2011). The precariat: the new dangerous class. London: Bloomsbury.

Thompson, R. (2011). Individualisation and social exclusion: the case of young people not in education, employment or training. Oxford Review of Education, 37(6), 785-802.

UGT (2005). Els altres joves [The other young people]. Barcelona: UGT.

Van de Velde, C. (2008). Devenir adulte. Sociologie comparée de la jeunesse en Europe. Paris: Presses Universitaires de France.

Walther, A. and Pohl, A. (2005). Thematic Study on Policy Measures concerning Disadvantaged Youth: Final Report. Tübingen: IRIS. 
Yates, S. and Payne, M. (2006). Not so NEET? A Critique of the Use of "NEET" in Setting Targets for Interventions with Young People. Journal of Youth Studies, 9(3), 329-344. 